\title{
OS EFEITOS MULTIPLICADORES AO NÍVEL DO PRODUTO E DO RENDIMENTO MEDIDOS ATRAVÉS DA MATRIZ DE CONTABILIDADE SOCIAL E DA ANÁLISE INPUT-OUTPUT $o$ caso dos agentes económicos de 6 pequenas e médias cidades portuguesas 1
}

Francisco Diniz ${ }^{2}$

Resumo: $O$ artigo faz uma análise de multiplicadores de emprego nas pequenas e médias cidades portuguesas utilizando-se da matriz de contabilidade social e da análise de insumo-produto. $\mathrm{O}$ estudo s constatou que as empresas localizadas nas áreas urbanas vendem mais, localmente, do que as que desenvolvem a sua actividade produtiva nas áreas rurais; constatou, igualmente, que as famílias residentes na cidade consomem mais, localmente, do que as que vivem no meio rural. Por conseguinte, a cidade é o local ideal para sediar empresas, isto é, para fazer novos investimentos. Apesar desta evidência, os multiplicadores indicam que, embora os multiplicadores da cidade possam ser maiores do que os que se verificam para as áreas rurais, na maior parte das vezes, o efeito multiplicador sentido nas áreas rurais é diminuto.

Palavras-chave: Contabilidade Social, Insumo-Produto, Emprego, Cidades Portuguesas.

\footnotetext{
1 The Role of Small and Medium-sized Towns in Rural Development - Marketowns -[EU RTD Project QLRT-2000-01923], foi coordenado pela Universidade de Reading e Plymouth. A equipa portuguesa foi coordenada por F. Diniz e foi composta por A. Poeta, C. Silva, L. Pinto, P. António e S. Abreu.

2 Doutor em Economia, Professor Associado do Centro de Estudos Transdisciplinares para o Desenvolvimento, Universidade de Trás-os-Montes e Alto Douro (CETRAD/DESG/UTAD), E-mail: fdiniz@utad.pt
} 


\begin{abstract}
This article makes an analysis of employment multipliers in small and medium-sized portuguese cities using the social accounting matrix and input-output analysis. The study found that companies located in urban areas sell more locally than those who develop their activities in rural areas, also, found that the families living in the urban areas consume more locally than those living in the rural side. Therefore, the city is ideal for hosting companies, that is, to make new investments. Despite this evidence, the multipliers indicate that while the multipliers of the city may be larger than those that exist for rural areas, in most cases, the multiplier effect in rural areas is low.
\end{abstract}

Key-words: Social Accounting, Input-Output, Employment, Portuguese Cities.

O objectivo desta comunicação é o de apresentar os resultados da análise input-output da Matriz de Contabilidade Social de Portugal aplicada em seis pequenas e médias cidades portuguesas. Serão discutidos os resultados obtidos pela aplicação do modelo input-output à Matriz de Contabilidade Social e os dados recolhidos em seis pequenas e médias cidades portuguesas, relativamente aos agentes económicos, famílias e empresas, no âmbito de um projecto de investigação financiado pela Comissão Europeia.

Começar-se-á por uma apresentação do enquadramento teórico inerente à construção da Matriz de Contabilidade Social e dos pressupostos e limitações do modelo input-output.

Em seguida, serão discutidos os resultados em termos dos efeitos multiplicadores tanto no que diz respeito ao produto gerado pelos diferentes sectores da actividade económica, como ao rendimento obtido pelas famílias sedeadas em seis pequenas e médias cidades. Estes efeitos serão analisados para as áreas urbanas e rurais dos concelhos onde as seis cidades, em estudo, estão situadas, com o fim de tecer algumas considerações sobre o papel dos agentes económicos destas cidades no desenvolvimento local.

\title{
CONSTRUÇÃO DA MATRIZ DE CONTABILIDADE SOCIAL (MCS) E DO MODELO INPUT-OUTPUT (IO)
}

\section{ENQUADRAMENTO TEÓRICO}

Um dos objectivos do projecto de investigação Marketowns foi a construção de uma Matriz de Contabilidade Social (MCS) para cada um 
dos países envolvidos - Reino Unido, França, Países Baixos, Polónia e Portugal - de modo a estudar as ligações económicas dentro e entre os diversos sectores de actividade económica e as famílias de uma determinada economia local. A MCS tem por base o modelo input-output de Leontief mas com um modelo que só cobre alguns fluxos detalhados do produto total da economia, consistindo numa ampla variedade de contas endógenas, conforme consta da Figura 1.

Pode ser descrito como um equilíbrio geral de sistema de dados de contas de rendimento e de despesa, ligando as actividades de produção, os factores de produção e as instituições (Famílias, Empresas e Estado) de uma determinada economia. Os diferentes sectores da economia geram valor acrescentado que remuneram os factores primários tais como as pessoas empregadas, que podem ser distinguidas entre os assalariados e os trabalhadores por conta própria e os vários tipos de outros factores de produção como os factores terra e capital da conta de produção. Por sua vez, os rendimentos gerados pelas actividades produtivas são geridos pelas diferentes instituições como as Famílias, as Empresas e o Estado. Depois de um processo de redistribuição, os rendimentos são usados sob a forma de despesas de consumo final, ou de poupanças. Este círculo fica fechado quando este consumo e estas poupanças resultam em produção adicional (Pyatt e Round, 1985).

A análise dos efeitos multiplicadores pode, assim, servir para medir o impacto que eventuais mudanças ocorridas na procura final possam vir a produzir no sistema económico como um todo, da produção ao rendimento. Este tipo de análises requer a divisão da MCS em contas endógenas e exógenas. Esta divisão é, necessariamente, determinada de forma exógena, uma vez que os choques a ser estudados dependem da forma como se escolhem as contas exógenas (Efstratoglou e Psaltopoulos, 1999). As contas endógenas são aquelas cujas mudanças ao nível de despesa provocam alterações no rendimento enquanto que, nas contas exógenas, se assume que as despesas são independentes de mudanças ocorridas no rendimento. A partir de uma conta exógena do resto do mundo, é possível estudar as simulações de mudanças no nível das Exportações e nas transferências das Famílias e do Estado. Uma conta exógena de capital permite analisar os efeitos de um aumento do nível de investimento, enquanto que, com uma conta exógena do Estado, podem ser simulados os efeitos de uma variação no nível de transferências para as empresas ou para as famílias. Neste estudo, o equilíbrio da linha do Estado, do Capital e do Resto do Mundo foi considerado como uma linha exógena e agregada (RM) que inclui todas as transacções que tiveram lugar fora da localidade. 
Figura 1. Esquema do modelo da MCS

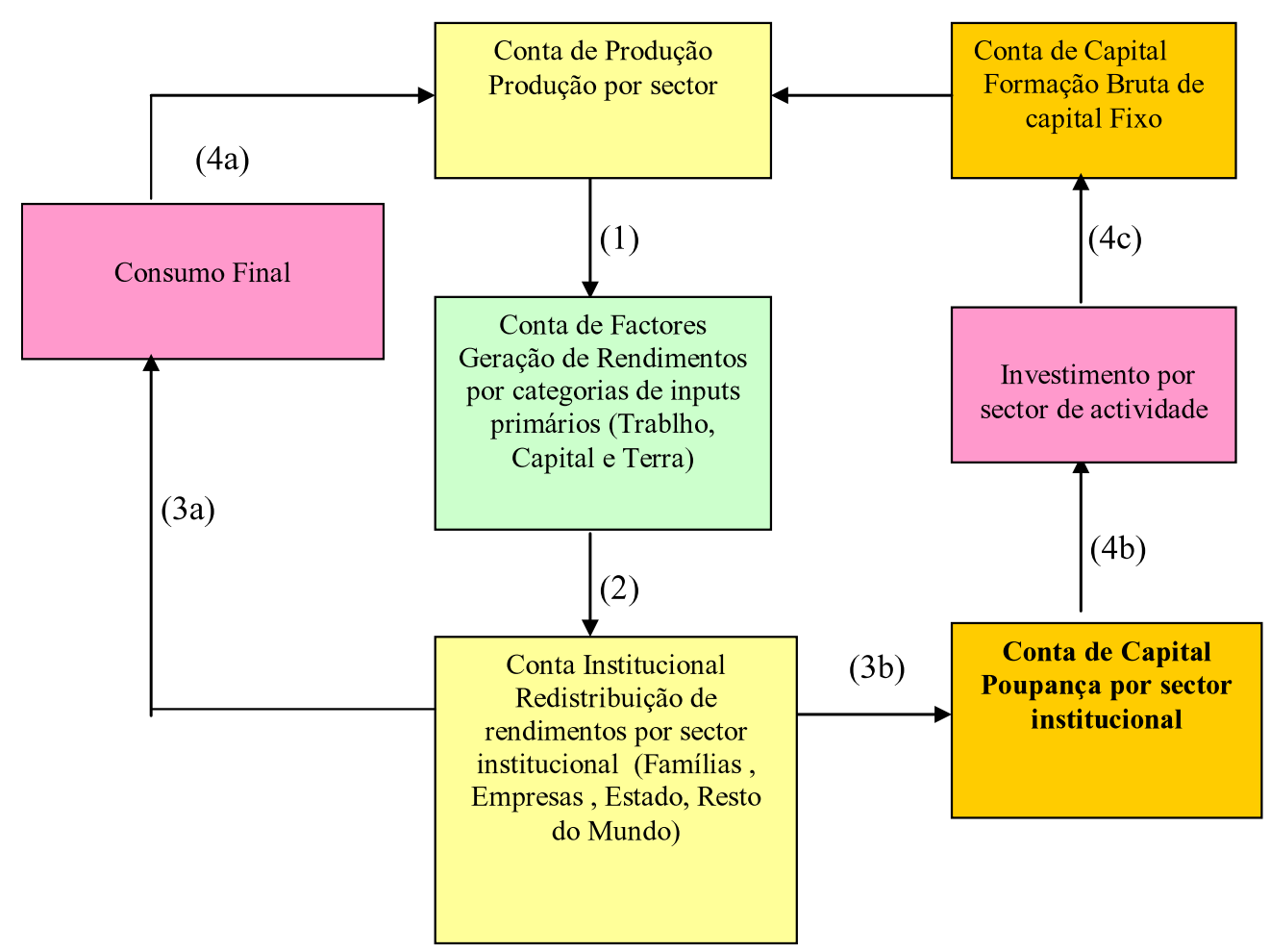

Fonte: Efstratoglou e Psaltopoulos (1999).

Neste trabalho, a MCS engloba as seguintes contas:

- Contas de Produção com 17 sectores (5 dos quais agrícolas) com actividade na cidade e na área rural envolvente - endógenas;

- Contas dos factores de produção com 4 grupos de habilitações (gestão, não - manual, manual qualificado e manual não qualificado) para a cidade e área rural envolvente - endógena;

- Contas da Família, dividida em grupos de rendimento por quartil para a cidade e área rural envolvente - endógena;

- A conta RM - Resto do Mundo para a cidade e área rural envolvente.

Uma lista detalhada pode ser consultada no Anexo 1. 


\section{MATRIZES DA CONTABILIDADE SOCIAL (MCS) INTER-REGIONAIS}

A maior parte dos estudos anteriores preocupou-se com as economias de um país analisado como um todo; contudo, na presente comunicação, o interesse principal tem a ver com unidades territoriais mais pequenas - pequenas e médias cidades e a sua área rural envolvente - pelo que se tornou necessário trabalhar a nível regional, criando, de igual modo, modelos inter-regionais em que os fluxos de bens, serviços e trabalho podem ser analisados para as cidades, áreas rurais envolventes e outros. Houve já, em trabalhos anteriores a este, a utilização de Modelos de MCS inter-regionais; no caso presente, o modelo usado teve por base o trabalho de Round (1985). Este autor usou uma abordagem similar para examinar as ligações rural - urbano na Malásia. Roberts (1998) seguiu um caminho semelhante para a analisar as ligações entre o rural e o urbano em Grampian, na Escócia. No projecto Marketowns é, contudo, a primeira vez que são estudadas ligações entre cidades específicas e o mundo rural envolvente, com um cariz eminentemente territorial. A recolha de dados permitiu obter informação desagregada importante a nível espacial para as actividades produtivas agrícolas e não agrícolas e para as famílias agrícolas e não agrícolas tanto residentes e localizadas na cidade, como no meio rural envolvente. Estes dados foram calibrados com outros dados secundários, tendo por base o método adoptado por Roberts (1998) para a região de Grampian.

O processo de modelação envolveu uma série de fases. A primeira foi a criação de um modelo input-output regional quer para a área urbana, quer para a área rural envolvente, com base no método da Geração de Matrizes Input-output Regional (GMIR). Esta é uma espécie de abordagem híbrida, envolvendo a aplicação de dados não recolhidos por questionário (uma combinação de um método mecânico de redução usando Quocientes de Localização Industrial Cruzados - QLIC e dados secundários regionais) e dados recolhidos por questionário.

A primeira fase do GMIR resulta numa redução dos coeficientes da Matriz input-output nacional através dos QLIC. Estes quocientes comparam o rácio de emprego, a nível nacional e regional, entre as indústrias vendedoras e compradoras, sendo utilizados dados de emprego nacionais e regionais para calcular os QLIC para todos os sectores do seguinte modo:

- Se o sector X, que aparece a nível nacional, não existe na cidade, então o QLIC é igual a zero. Consequentemente, todas as necessidades regionais são importadas e a procura intermédia regional é transferida para as importações; 
- Se o QLIC para dois sectores é maior ou igual a 1, é assumido que a oferta regional encontra a procura do sector comprador com o mesmo padrão do que se verifica a nível nacional e a figura de uma procura intermédia regional e da primazia de dos inputs é aceite;

- Se o QLIC é maior que zero mas menor que 1, assume-se que a produção das cidades é menos disponível que a nível nacional; nesse caso, é necessário recorrer à importação para repor o défice. Então, o fluxo da Matriz regional deve ser reduzido, multiplicando o fluxo desajustado pelo respectivo QLIC regional. Se houver valores residuais, estes devem ser somados às importações regionais.

Num segundo passo do método da Geração de Matriz Input-output Regionais - GMIR -, muitos dos coeficientes das matrizes IO serão substituídos com a informação mais apurada e desagregada disponível, através da informação recolhida por questionário acerca das despesas das famílias, dos seus rendimentos, das compras e vendas das actividades económicas, do emprego gerado em cada sector de actividade e dos salários pagos pelas mesmas às famílias. Os quadros 1 e 2 expressam os critérios de selecção das cidades e o volume de informação recolhida.

Quadro 1 - Critérios para a selecção das cidades

\begin{tabular}{|c|c|c|}
\hline $\begin{array}{l}\text { Cidades de acordo com a sua dimensão em termos do número de } \\
\text { habitantes }\end{array}$ & $\begin{array}{l}\text { Pequenas } \\
(5000-2000)\end{array}$ & $\begin{array}{c}\text { Médias } \\
(20000-40000)\end{array}$ \\
\hline Área onde o emprego na agricultura está muito acima da média nacional & Mirandela & Vila Real \\
\hline Área onde o emprego no turismo está muito acima da média nacional & Tavira & Silves \\
\hline Área perto de uma grande região metropolitana & Lixa & Esposende \\
\hline
\end{tabular}

Quadro 2 - Número de inquéritos a realizados

\begin{tabular}{|c|c|c|c|}
\hline Cidades agrícolas & Cidades turísticas e peri-urbanas & Urbana/Rural \\
\hline $\begin{array}{c}\text { Famílias não - agrícolas: área } \\
\text { urbana 100; área rural 50. }\end{array}$ & $\begin{array}{c}\text { Famílias não agrícolas: área urbana } \\
\text { 100; área rural 50. }\end{array}$ & $\begin{array}{c}\text { Empresas não } \\
\text { agrícolas }\end{array}$ & $603 / 364$ \\
\hline $\begin{array}{c}\text { Empresas não - agrícolas: área } \\
\text { urbana 100; área rural 30 }\end{array}$ & $\begin{array}{c}\text { Empresas não - agrícolas: área } \\
\text { urbana 100; área rural 50 }\end{array}$ & Empresas agrícolas & 257 \\
\hline Empresas agrícolas: 100; & Empresas agrícolas: 30 & Famílias não agrícolas & $600 / 305$ \\
\hline Famílias agrícolas: 100. & Famílias agrícolas: 30 & Famílias não agrícolas & 257 \\
\hline
\end{tabular}

As diferentes fontes de dados foram calibradas e reconciliadas num contexto consistente inter - regional. De acordo com a Figura 2 teve que se proceder ao equilíbrio da MCS para se fazer corresponder a soma das linhas (outputs) às colunas (inputs) que como se sabe tem que ser igual. A 
Conta exógena ROW serviu para o balanceamento e o recurso a peritos locais validou os procedimentos adoptados.

Figura 2 - Procedimentos na construção da MCS inter - regional

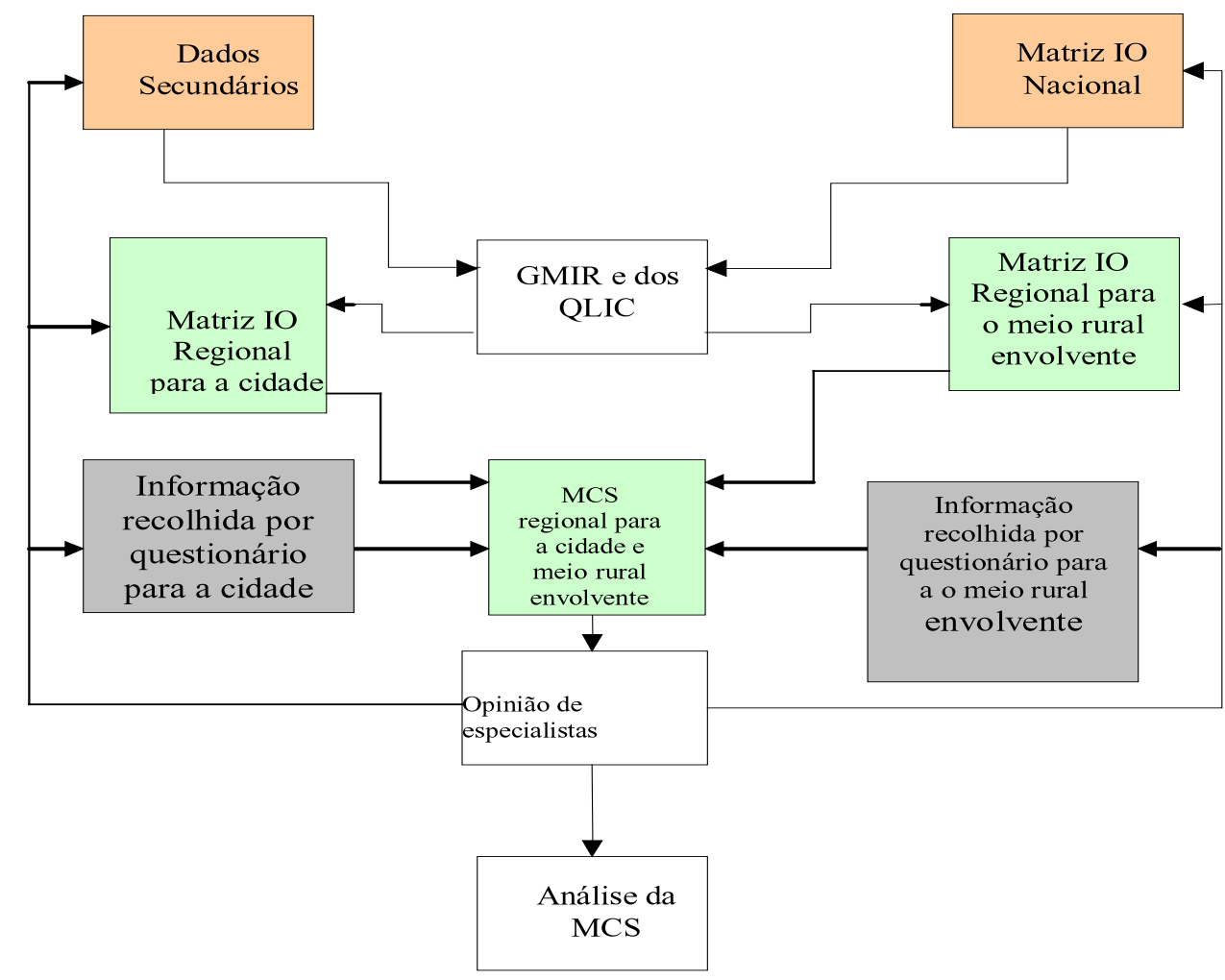

A MCS inter -regional construída no projecto Marketowns contém 4 sub-matrizes:

1. Matriz das transacções dentro da cidade:

2. Matriz das transacções da cidade com o meio rural envolvente;

3. Matriz das transacções do meio rural com a cidade;

4. Matriz das transacções dentro do meio rural envolvente.

Os anexos 2 e 3 apresentam, de forma detalhada, estas MCS, bem como as fontes dos dados para cada sub-matriz. 


\section{A Matriz Agregada}

O modelo inter-regional apresentará a seguinte forma:

$$
\underline{x}=G \underline{x}+\underline{f}
$$

Em que:

$$
\left(\begin{array}{l}
x_{1} \\
x_{2} \\
x_{3} \\
x_{4} \\
x_{5} \\
x_{6}
\end{array}\right)=\left(\begin{array}{ccc|ccc}
B_{11} & 0 & C_{11} & B_{12} & 0 & C_{12} \\
V_{11} & 0 & 0 & V_{12} & 0 & 0 \\
0 & Y_{11} & 0 & 0 & Y_{12} & 0 \\
\hline B_{21} & 0 & C_{21} & B_{22} & 0 & C_{22} \\
V_{21} & 0 & 0 & V_{22} & 0 & 0 \\
0 & Y_{21} & 0 & 0 & Y_{22} & 0
\end{array}\right)\left(\begin{array}{c}
x_{1} \\
x_{2} \\
x_{3} \\
x_{4} \\
x_{5} \\
x_{6}
\end{array}\right)+\left(\begin{array}{l}
f_{1} \\
f_{2} \\
f_{3} \\
f_{4} \\
f_{5} \\
f_{6}
\end{array}\right) .
$$

Para cada sub-matriz (transacções inter-urbanas, entre o meio urbano $r$ rural e entre o meio rural e o urbano) podem ser definidas as seguintes matrizes:

B : matriz dos coeficientes input-output

$\mathrm{V}$ : matriz dos coeficientes do rendimento do trabalho

$C$ : matriz dos coeficientes da despesas dos agregados familiares

$Y$ : matriz dos coeficientes que representam a distribuição dos rendimentos do trabalho entre os agregados familiares

$x$ : vector do out-put total

$f$ : vector da conta dos fluxos exógenos.

Re-arranjando a matriz pode-se escrever a equação através de um sistema 6 por 6 ,

$$
\left(\begin{array}{ccc|ccc}
I-B_{11} & 0 & -C_{11} & B_{12} & 0 & -C_{12} \\
V_{11} & I & 0 & -V_{12} & 0 & 0 \\
0 & Y_{11} & I & 0 & -Y_{12} & 0 \\
\hline-B_{21} & 0 & -C_{21} & I-B_{22} & 0 & -C_{22} \\
-V_{21} & 0 & 0 & -V_{22} & I & 0 \\
0 & -Y_{21} & 0 & 0 & -Y_{22} & I
\end{array}\right)\left(\begin{array}{c}
x_{1} \\
x_{2} \\
x_{3} \\
\frac{x_{4}}{x_{5}} \\
x_{5} \\
x_{6}
\end{array}\right)=\left(\begin{array}{c}
f_{1} \\
f_{2} \\
f_{3} \\
f_{4} \\
f_{5} \\
f_{6}
\end{array}\right) .
$$

Sendo $A=\left(\begin{array}{ccc|ccc}I-B_{11} & 0 & -C_{11} & B_{12} & 0 & -C_{12} \\ V_{11} & I & 0 & -V_{12} & 0 & 0 \\ 0 & Y_{11} & I & 0 & -Y_{12} & 0 \\ \hline-B_{21} & 0 & -C_{21} & I-B_{22} & 0 & -C_{22} \\ -V_{21} & 0 & 0 & -V_{22} & I & 0 \\ 0 & -Y_{21} & 0 & 0 & -Y_{22} & I\end{array}\right)$ pode ser expresso de uma

forma mais simples do seguinte modo: 


$$
A \underline{x}=\underline{f}
$$

Resolvendo a equação para o vector $\underline{x}$ dado que $A$ é uma matriz não-singular, pode dizer-se que $\underline{x}=A^{-1} \underline{f}$. Aqui, $A^{-1}$ permite o cálculo do multiplicador agregado inter-regional.

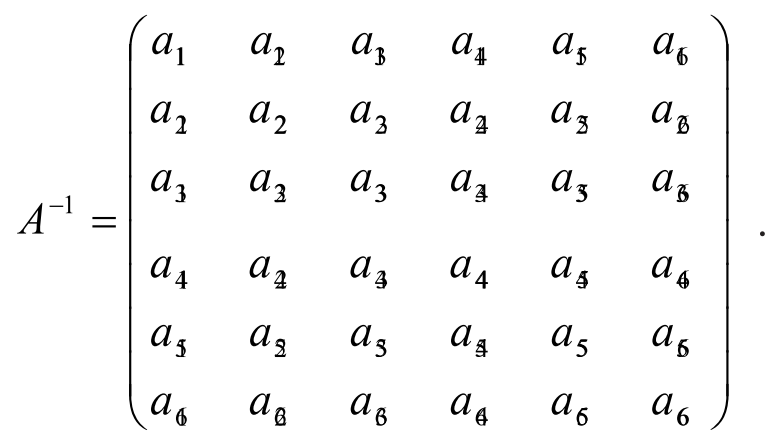

A matriz $A^{-1}$ da equação (5) dará o multiplicador do produto para a região como um todo (área urbana e meio rural). Quanto mais próxima estiver a matriz do multiplicador da matriz identidade, mais fraco será o respectivo efeito multiplicador. Observando-se as contas em separado da matriz $A^{-1}$, pode ser interpretado o potencial impacto de mudanças exógenas na conta $f$ em diversos sectores, factores de produção e níveis de rendimento. A soma das colunas na primeira sub-matriz $a_{11}$ indica o impacto de uma mudança exógena ocorrida na procura nos diferentes sectores de produção da cidade $X_{1}$ na produção total da cidade. A soma das colunas $a_{21}$ e $a_{31}$ indica o impacto de mudanças na procura do sector $X_{1}$ da cidade nos salários e nos rendimentos das famílias da cidade, respectivamente. A soma das colunas $a_{41}$ indicando impacto de mudanças na procura dos sectores de produção da $X_{1}$ cidade nos sectores de produção do meio rural, enquanto que $a_{51}$ e $a_{61}$ indicam os seu impactos nos salários e no rendimento das famílias do meio rural, respectivamente. Assim, $a_{12}$ indica o impacto de uma injecção exógena para a conta do factor $X_{2}$ da cidade na produção do meio urbano. $a_{22}$ e $a_{23}$ indicam o impacto de mudanças nos salários e do rendimento das famílias, etc. A interpretação das outras sub-matrizes do sistema acima referido e similar à anteriormente apresentada. 


\section{Decomposição da matriz agregada}

A primeira parte da análise é baseada na interpretação do impacto total dentro das regiões causado por uma qualquer mudança acima apresentada. Contudo, os multiplicadores podem ser fraccionados usando para tal o método desenvolvido por Round (1989) que permite ver a extensão do impacto gerado. Os multiplicadores são decompostos de tal modo que o impacto inicial dentro do meio urbano ou do meio rural é separado permitindo seguir as repercussões sentidas na outra zona e de que forma é que estas repercussões têm um efeito de retorno na zona original. Não se está à procura onde é que o impacto final da mudança é sentido, mas sim quanto desse impacto é gerado dentro da zona original e quanto é que vai parar a outras zonas, isto é vai de da área urbana para a rural ou vice-versa. A matriz é considerada como sendo 2 por 2 dividindo-se em quadrantes mostrado as relações cidade - cidade, cidade - rural, rural -cidade e rural cidade.

Para encontrar todos os multiplicadores interdependentes pode exprimir-se $A^{-1}$ como o produto de três matrizes

$$
\underline{x}=M_{3} M_{2} M_{1} \underline{f}
$$

Em que, $M_{1}$ representa a matriz dos multiplicadores inter-regionais indicando as ligações dos efeitos entre as contas endógenas e no todo da cidade ou do meio rural.

$M_{2}$ poder visto como os efeitos multiplicadores dos fluxos cruzados entre a cidade e o meio rural capturando os efeitos da cidade do meio rural e vice-versa.

$M_{3}$ indica o fechar do ciclo da matriz de multiplicadores, mostrado os efeitos de injecção da cidade (ou no meio rural) neles próprios através da endogeneização definindo as ligações dentro do meio rural (ou da cidade), relembrado que $M_{1}$ tem efeitos de retorno.

No modelo que a seguir se apresenta as letras representam grupos de elementos da matriz input-output e de vectores: 
$X_{T}$ Vector output para a cidade.

$X_{H}$ Vector output para o meio rural.

$f_{T}$ Vector da procura final para a cidade.

$f_{H}$ Vector procura final para o meio rural.

$T_{T}$ Matriz dos elementos que representam as transacções dentro da cidade.

$T_{H}$ Matriz dos elementos que representam as transacções da cidade com o meio rural.

$H_{T}$ Matriz dos elementos que representam as transacções do meio rural para a cidade.

$H_{H}$ Matriz dos elementos que representam as transacções dentro do meio rural.

A equação inicial do modelo é dado por:

$$
\left[\begin{array}{l}
x_{T} \\
x_{H}
\end{array}\right]=\left[\begin{array}{ll}
T_{T} & H_{T} \\
T_{H} & H_{H}
\end{array}\right]\left[\begin{array}{l}
x_{T} \\
x_{H}
\end{array}\right]+\left[\begin{array}{l}
f_{T} \\
f_{H}
\end{array}\right]
$$

Isto pode ser factorizado e então,

$$
\left[\begin{array}{cc}
I-T_{T} & -H_{T} \\
-T_{H} & I-H_{H}
\end{array}\right]\left[\begin{array}{l}
x_{T} \\
x_{H}
\end{array}\right]=\left[\begin{array}{l}
f_{T} \\
f_{H}
\end{array}\right]
$$

Uma expressão para as variáveis do produto pode ser obtida encontrando a matriz inversa:

$$
\left[\begin{array}{l}
x_{T} \\
x_{H}
\end{array}\right]=\left[\begin{array}{cc}
I-T_{T} & -H_{T} \\
-T_{H} & I-H_{H}
\end{array}\right]^{-1}\left[\begin{array}{l}
f_{T} \\
f_{H}
\end{array}\right]
$$

Uma expressão algébrica para a inversa pode ser encontrada em termos das sub-matrizes a partir de (7)

$$
\left[\begin{array}{cc}
I-T_{T} & 0 \\
0 & I-H_{H}
\end{array}\right]\left[\begin{array}{l}
x_{T} \\
x_{H}
\end{array}\right]=\left[\begin{array}{cc}
0 & H_{T} \\
T_{H} & 0
\end{array}\right]\left[\begin{array}{l}
x_{T} \\
x_{H}
\end{array}\right]+\left[\begin{array}{l}
f_{T} \\
f_{H}
\end{array}\right]
$$

Multiplicando pela inversa obtém-se: 


$$
\left[\begin{array}{c}
x_{T} \\
x_{H}
\end{array}\right]=\left[\begin{array}{cc}
I-T_{T} & 0 \\
0 & I-H_{H}
\end{array}\right]^{-1}\left[\begin{array}{cc}
0 & H_{T} \\
T_{H} & 0
\end{array}\right]\left[\begin{array}{l}
x_{T} \\
x_{H}
\end{array}\right]+\left[\begin{array}{cc}
I-T_{T} & 0 \\
0 & I-H_{H}
\end{array}\right]^{-1}\left[\begin{array}{l}
f_{T} \\
f_{H}
\end{array}\right]
$$

Definindo $\hat{T}=\left(I-T_{T}\right)^{-1}$ e $\hat{H}=\left(I-H_{H}\right)^{-1}$ pode escrever-se a equação do seguinte modo:

$$
\left[\begin{array}{l}
x_{T} \\
x_{H}
\end{array}\right]=\left[\begin{array}{cc}
0 & \hat{T} H_{T} \\
\hat{H} T_{H} & 0
\end{array}\right]\left[\begin{array}{l}
x_{T} \\
x_{H}
\end{array}\right]+\left[\begin{array}{cc}
\hat{T} & 0 \\
0 & \hat{H}
\end{array}\right]\left[\begin{array}{l}
f_{T} \\
f_{H}
\end{array}\right]
$$

Factorizando uma vez mais, dará o seguinte:

$$
\left[\begin{array}{cc}
I & -\hat{T} H_{T} \\
-\hat{H} T_{H} & I
\end{array}\right]\left[\begin{array}{l}
x_{T} \\
x_{H}
\end{array}\right]=\left[\begin{array}{cc}
\hat{T} & 0 \\
0 & \hat{H}
\end{array}\right]\left[\begin{array}{l}
f_{T} \\
f_{H}
\end{array}\right]
$$

Resolvendo obter-se-á o vector de output

$$
\left[\begin{array}{l}
x_{T} \\
x_{H}
\end{array}\right]=\left[\begin{array}{cc}
I & -\hat{T} H_{T} \\
-\hat{H} T_{H} & I
\end{array}\right]^{-1}\left[\begin{array}{ll}
\hat{T} & 0 \\
0 & \hat{H}
\end{array}\right]\left[\begin{array}{l}
f_{T} \\
f_{H}
\end{array}\right]
$$

A matriz inversa pode ser expressa do seguinte modo:

$$
\left[\begin{array}{c}
x_{T} \\
x_{H}
\end{array}\right]=\left[\begin{array}{cc}
\left(I-\hat{T} H_{T} \hat{H} T_{H}\right)^{-1} & 0 \\
0 & \left(I-\hat{H} T_{H} \hat{T} H_{T}\right)^{-1}
\end{array}\right]\left[\begin{array}{cc}
I & \hat{T} H_{T} \\
\hat{H} T_{H} & I
\end{array}\right]\left[\begin{array}{cc}
\hat{T} & 0 \\
0 & \hat{H}
\end{array}\right]\left[\begin{array}{l}
f_{T} \\
f_{H}
\end{array}\right]
$$

Ou escrita do seguinte modo:

$$
\left[\begin{array}{l}
x_{T} \\
x_{H}
\end{array}\right]=M_{3} M_{2} M_{1}\left[\begin{array}{l}
f_{T} \\
f_{H}
\end{array}\right]
$$

Combinando as três matrizes $M$, dará 


$$
\left[\begin{array}{cc}
\left(I-\hat{T} H_{T} \hat{H} T_{H}\right)^{-1} \hat{T} & \left(I-\hat{T} H_{T} \hat{H} T_{H}\right)^{-1} \hat{T} H_{T} \hat{H} \\
\left(I-\hat{H} T_{H} \hat{T} H_{T}\right)^{-1} \hat{H} T_{H} \hat{T} & \left(I-\hat{H} T_{H} \hat{T} H_{T}\right)^{-1} \hat{H}
\end{array}\right]
$$

O produto da matriz tripla acima é certamente equivalente à inversa da matriz da equação (7). Calculando as três matrizes anteriormente referidas é fácil obter a matriz inversa total da equação (7) e as duas inversas mais pequenas $\hat{T}$ e $\hat{H}$.

As diagonais em $M_{1}$ serão dadas por $\hat{T}$ e $\hat{H}$. Os termos da diagonal em $M_{2}$ será também facilmente calculados. A diagonal em $M_{3}$ será encontrada através das sub-matrizes na diagonal da matriz inversa total multiplicando por $\hat{T}^{-1}$ a qual por sua vez é $\left(I-T_{T}\right)$.

\section{Multiplicadores do emprego}

Os multiplicadores do emprego proporcionam uma informação importante acerca dos diferentes impactos de mudanças no emprego de cada sector. Os multiplicadores do emprego e podem ser expressos como uma combinação dos multiplicadores do produto $\underline{x}$ e os coeficientes dos emprego directo e' (emprego por output do sector).

$$
\begin{aligned}
& \mathrm{e}^{\prime}=E(X)^{-1} \\
& E=\hat{\mathrm{e}} A^{-1} f
\end{aligned}
$$

No qual $E$ reflecte o número de empregos respectivamente nos sectores da área urbana e rural e ê é a matriz com os coeficientes do emprego na diagonal. Este modelo produzirá os multiplicadores do emprego para toda a região (urbana e rural), os quais podem ser interpretados da maneira que a seguir se apresenta. As somas das colunas na primeira sub-matriz êa ${ }_{11}$ mostra o impacto de um aumento exógeno da procura para os sectores de produção $X_{1}$ no emprego dos sectores de produção da cidade. As sub-matrizes êa ${ }_{31}$ mostram o impacto de uma mudança na procura do sector de produção no emprego das famílias da cidade. Assim, êa ${ }_{12}$ reflecte o impacto de uma injecção exógena nos factores de produção $X_{2}$ da cidade no emprego dos sectores produtivos da cidade, etc. 
Por último, os coeficientes na linha da conta exógena ROW da MCS indicam as ligações dos sistemas tais como procura importada ou receitas governamentais.

As ligações $L$ podem ser expressas pela equação (11)

$$
L=B x
$$

Em que, $B$ é a matriz rectangular $(\mathrm{m} \times \mathrm{n})$ dos coeficientes com a conta exógena como linha e a conta endógena como coluna.

\section{Pressupostos e limitações do modelo}

\subsubsection{Pressupostos da MCS e do modelo input-output}

Como em todas as análises que têm por base os modelos de input-output, alguns pressupostos são tidos em consideração e por conseguintes estes devem ser tidos em devida conta quando se discutem os resultados obtidos. Sobretudo quando se pretende influencias decisões políticas para os territórios em questão.

Em primeiro lugar, considera-se que as funções de produção são lineares. Muitas das mudanças ocorrerão na margem e os valores estimados baseados em relações médias sobrestimarão os impactos dos sectores. Assume-se também que todos os recursos estão a ser utilizados no pleno emprego e, por isso, qualquer mudança no sistema terá um impacto nos recursos necessários o que na maior parte das vezes não acontece por se estar em sub-emprego da utilização dos factores produtivos trabalho e capital.

Em segundo lugar, é assumido que o output de cada sector é homogéneo (i.e. do mesmo tipo e qualidade). Este problema é tanto maior quanto maior for o nível de agregação Por exemplo, uma mudança no produto do sector agro-alimentar terá influência em todos cós sectores que com este sector mantêm relações comerciais de compra e venda mas se este sector for uma parte do sector da indústria transformadora perde-se esta informação.

Em terceiro lugar, assume-se que há uma estrutura única do mercado de factores de produção dentro de cada sector de actividade e não haverá substituição de factores.

Em quarto e último lugar, assume-se que a propensão marginal ao consumo é idêntica para todos os agregados familiares o que pode sobrestimar os efeitos multiplicadores para rendimento das famílias. 
A dimensão da economia local cria problemas na elaboração dos modelos. Um dos principais está na pequena parte dos inputs e outputs que as empresas vão buscar ou retêm na economia local, tornando, por conseguinte os coeficientes muito pequenos ou mais propensos a erros estatísticos. De igual a pequena dimensão da economia local torna ainda mais importante a classificação das empresas por sectores de actividade. Uma agro-indústria localizada na área em estudo pose ser menos influenciada por uma mudança do que a que o modelo indica. Por exemplo uma empresa de moagem que venda a farinha a uma pastelaria venderá no caso do modelo para a indústria agro-alimentar. Há muitas indústrias deste sector nas Zonas urbanas e rurais mas não há nenhuma pastelaria. Se houver um impacto na economia local que afectará a empresa de moagem haverá um impacto na indústria agro-alimentar pese embora o impacto das vendas de farinha se faça sentir fora da localidade e, por conseguinte, os multiplicadores a estimados será exagerados.

Estar-se-á, assim, perante um dilema. O erro estatístico pode ser reduzido através de uma maior agregação embora tal torne mais difícil determinar quais em empresas estão na verdade presentes pela sua procura de inputs na economia local.

Os passos dados na construção da MCS inter-regional revelaram vários problemas de conciliação dos dados recolhidos ao nível micro-regional urbano e rural com os dados ao nível macro.

No caso português o INE providenciou uma Matriz I/O com alguns problemas de equilíbrio que foram resolvidos pela equipa do projecto Marketowns para que houvesse a possibilidade de comparar resultados.

\section{ANÁLISE DOS MULTIPLICADORES PARA AS MATRIZES DA CONTABILIDADE SOCIAL (MCS) INTER-REGIONAIS}

Nesta secção, tentar-se-á deduzir os diferentes multiplicadores retirados da MCS. Os multiplicadores input-output convencionais investigam, somente, os impactos causados por mudanças na procura exógena de sectores produtivos noutros sectores produtivos, enquanto que o modelo da MCS permite ver o impacto de injecções exógenas em todas as variáveis endógenas, tais como remunerações de factores produtivos e rendimentos das famílias. Assim, através do processo de inversão da matriz, poder-se-á ver não somente como uma mudança externa terá impacto no nível de produção mas, também, no rendimento das famílias e no seu padrão de consumo, ou seja, no nível da despesa, indicando, por conseguinte, de forma mais real, a natureza das interdependências dentro da economia local. 
De uma maneira geral, os multiplicadores são um caminho conveniente para expressar como a mudança num sector tem impacto na economia como um todo. Podem ser calculados 3 efeitos:

- Efeitos directos: Efeitos na produção de um sector quando a produção se expande;

- Efeitos indirectos: O aumento de produção de um sector causará aumentos no nível de produção de outros sectores que fornecem inputs;

- Efeitos induzidos: Um aumento adicional da actividade económica, estimulada pelo aumento de gastos das famílias causados por aumentos dos salários terá efeitos no nível de produção.

Todos estes efeitos podem ser quantificados através de multiplicadores onde:

- Multiplicadores Tipo I = (Efeito directo + Efeito indirecto $) /$ Efeito directo

- Multiplicadores Tipo II = (Efeito directo + Efeito indirecto + Efeito induzido) / Efeito directo

Os multiplicadores gerados pela análise da MCS no projecto Marketowns pertencem ao último tipo. Em primeiro lugar calculou-se o multiplicador do produto que indica o ajustamento no produto total, das zonas urbanas e rurais, associado a uma mudança unitária do produto de um sector particular. Por exemplo, um multiplicador igual a 1,87 para o sector leiteiro significa que um aumento de 1 milhão de euros (devido a um aumento das exportações, consumo ou investimento) provocará uma expansão de 1,87 milhões $€$ no produto regional. Inputs adicionais de concentrados, energia, água ou um contrato gerará produção adicional nos respectivos sectores de actividade económica que, por sua vez, exigirão inputs de outros sectores.

De uma perspectiva de desenvolvimento regional os coeficientes de emprego e de rendimento são, de igual modo, interessantes. Os coeficientes directos de rendimento indicam o rendimento associado a cada milhão de Euros ocorrido no nível de produção. Assim, um coeficiente directo de rendimento igual a 0,15 para o sector leiteiro indica que 1 milhão de euros de produção leiteira dará $150000 €$ de rendimento directo. Por outro lado, um coeficiente directo, indirecto e induzido de 0,377 sugere 
que cada milhão de euros de produção do sector leiteiro está associado a $377000 €$ de rendimento na economia regional. O coeficiente directo de emprego indica o número de postos de trabalho associados a 1 milhão de euros de produto, enquanto que os coeficientes directos, indirectos e induzidos mostram o efeito total no emprego da economia regional.

Os multiplicadores de rendimento das famílias reflectem o impacto na economia regional de 1 milhão de euros injectados nos rendimentos das famílias. Por exemplo, um multiplicador de rendimento das famílias de 1,64 pode ser interpretado como se 1 milhão de euros injectados numa família média resultasse num aumento do nível de rendimento familiar regional de $640000 €$. O multiplicador do emprego indica o emprego adicional gerado na economia regional devido a um aumento do emprego num determinado sector de actividade económica.

Assumindo o mesmo pressuposto dos multiplicadores input-output de que os coeficientes da estrutura da matriz input-output são constantes ( i.e. que a média da propensão ao consumo da MCS é igual à propensão marginal de cada conta), pode-se derivar os multiplicadores através de uma MCS inter-regional para demonstrar o impacto nas zonas urbanas e rurais de um choque externo. Pode-se, igualmente, decompor os multiplicadores da MCS em inter-regional e intra-regional. Os multiplicadores intra-regionais representam os efeitos de transacções dentro da zona urbana ou rural, enquanto que os multiplicadores inter-regionais representam os efeitos das transacções entre a cidade e o meio rural e vice-versa. Isto ajuda a perceber a forma de dependência entre as duas zonas.

Os multiplicadores gerados pela análise da MCS proporcionam um melhor entendimento do potencial do processo de crescimento/desenvolvimento económico regional e podem ser uma importante ajuda para se perceber o papel que pequenas e médias cidades podem ter na criação de pólos de crescimento/desenvolvimento para as áreas rurais envolventes.

\section{ANÁLISE DOS RESULTADOS MULTIPLICADORES OBTIDOS PARA AS MATRIZES DA CONTABILIDADE SOCIAL (MCS) INTER-REGIONAIS DE SEIS CIDADES PORTUGUESAS SEDEADAS EM MEIO RURAL}

As figuras seguintes comparam os padrões dos multiplicadores obtidos para as seis cidades portuguesas anteriormente referidas, ilustrando as diferenças da dimensão dos efeitos por tipo de cidade, por dimensão e por localização, em meio rural ou urbano, dos choques externos. 
A figura 3 apresenta os efeitos multiplicadores do produto, para a média dos sectores produtivos causados por um choque externo na procura inicial, ocorrido nas zonas urbanas e rurais, respectivamente, em cada uma das seis cidades portuguesas estudadas no projecto Marketowns.

O efeito multiplicador do produto é maior quando o choque externo tem lugar nas áreas rurais das cidades agrícolas, não importando a sua dimensão. O mesmo acontece na cidade turística de dimensão média e na pequena cidade peri-urbana. Nas cidades turísticas, a dimensão é determinante uma vez que o facto do choque externo ter ocorrido na área urbana pode provocar um efeito multiplicador mais significativo. Em Esposende, cidade peri-urbana de média dimensão, não existe diferença nos efeitos multiplicadores quando o choque ocorre nas áreas rurais ou urbanas.

Figura 3 - Multiplicadores do produto na área urbana e rural

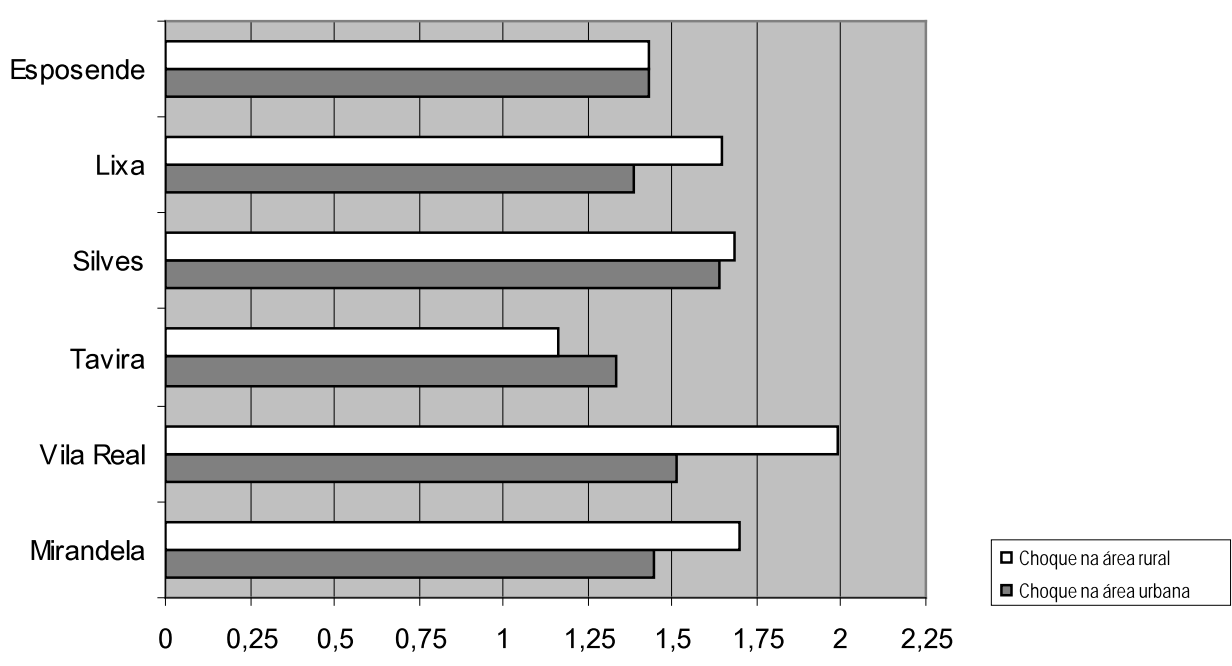

A figura 4 compara os efeitos multiplicadores do rendimento das famílias para o caso de uma família padrão, em termos de classe social, nas seis cidades portuguesas estudadas, independentemente do choque externo ter tido lugar na área urbana, ou na zona rural envolvente.

Os efeitos multiplicadores maiores no rendimento das famílias ocorrem entre as que residem em cidades peri-urbanas, seguidos, de perto, pelos das cidade agrícolas. Em último lugar nos efeitos multiplicadores das famílias, estão as cidades turísticas. Será de salientar o facto de as famílias residentes na área rural dos concelhos das cidades turística e do concelho da cidade média agrícola terem maiores efeitos multiplicadores no seu rendimento. A situação inversa é verificada em todas as outras cidades. 
Figura 4 - Multiplicadores do rendimento das famílias

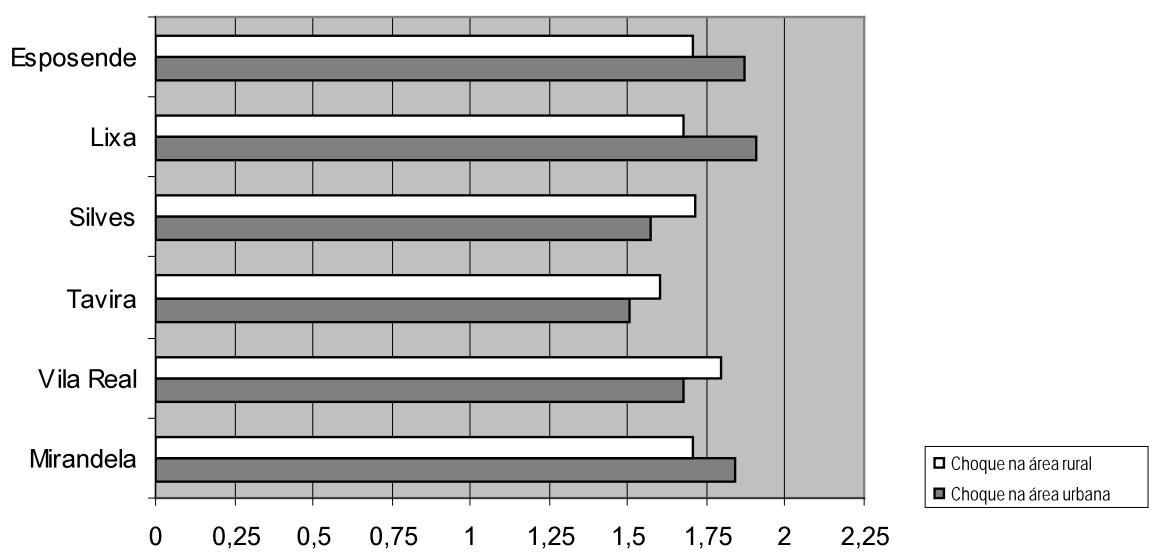

A figura 5 compara os efeitos multiplicadores dos salários para o caso da qualificação dos trabalhadores em termos da sua formação e capacitação, nas seis cidades portuguesas estudadas, quer o choque externo tenha tido lugar na área urbana ou na zona rural envolvente.

Mais uma vez, é nas cidades agrícolas que se verifica o maior efeito multiplicador dos salários. Em todas os tipos de cidades, a dimensão faz aumentar os efeitos multiplicadores dos salários. Nas de média dimensão, estes são maiores quando o choque ocorre na zona rural, enquanto que, nas de pequena dimensão, os efeitos multiplicadores dos salários são maiores quando o choque externo tem lugar na área urbana dos concelhos onde as mesmas estão sedeadas.

Figura 5 - Multiplicadores dos salários

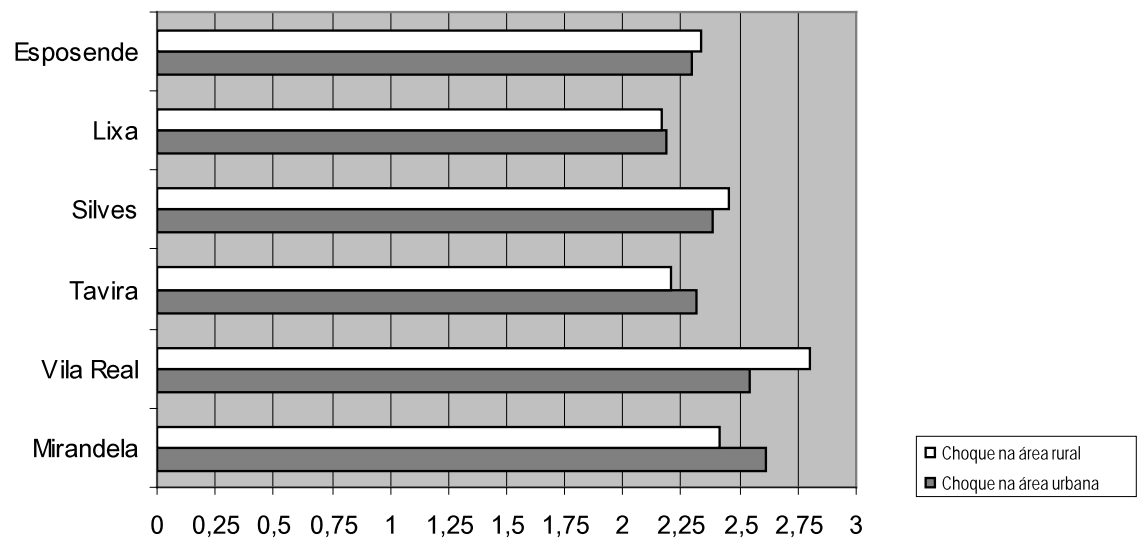


O quadro que seguinte indica os multiplicadores do produto para os sectores produtivos chave das zonas áreas urbanas logo seguidos da $\mathrm{Ad}$ ministração Pública. Dos sectores chave das zonas rurais são os ligados à indústria transformadora, seguido de perto pela construção e dos serviços e só por fim agricultura.

Quadro 3 - Multiplicadores do produto para sectores chave da zona urbana e rural de cidades portuguesas e seus impactos na outra zona

\begin{tabular}{|c|c|c|c|}
\hline \multicolumn{2}{|c|}{$\begin{array}{c}\text { Impacto no produto na zona urbana e rural causado por } \\
\text { um choque exógeno ocorrido na zona urbana }\end{array}$} & \multicolumn{2}{|c|}{$\begin{array}{c}\text { Impacto no produto na zona urbana e rural causado por } \\
\text { um choque exógeno ocorrido na zona rural }\end{array}$} \\
\hline Sector chave/urbano & $\begin{array}{c}\text { Impacto no } \\
\text { produto na } \\
\text { zona urbana e } \\
\text { rural }\end{array}$ & Sector chave/rural & $\begin{array}{c}\text { Impacto no } \\
\text { produto na } \\
\text { zona urbana e } \\
\text { rural }\end{array}$ \\
\hline \multicolumn{4}{|c|}{ Mirandela: cidade agrícola - pequena } \\
\hline Hotéis e restauração & 1,599 & Produção animal & 1,953 \\
\hline Outros serviços & 1,463 & Construção & 1,690 \\
\hline Administração pública & 1,268 & Têxteis/madeira e curtumes & 1,660 \\
\hline \multicolumn{4}{|c|}{ Vila Real: cidade agrícola - média } \\
\hline Construção & 1,663 & Transportes e serviços & 2,113 \\
\hline Outros serviços & 1,627 & Construção & 1,729 \\
\hline Hotéis e restauração & 1,508 & Agro-indústrias & 1,710 \\
\hline \multicolumn{4}{|c|}{ Tavira: cidade turística - pequena } \\
\hline Hotéis e restauração & 1,283 & Têxteis/madeira e curtumes & 1,597 \\
\hline Outros serviços & 1,221 & Agro-indústrias & 1,547 \\
\hline Administração pública & 1,187 & Construção & 1,467 \\
\hline \multicolumn{4}{|c|}{ Silves: cidade turística - média } \\
\hline Administração pública & 1,621 & Maquinaria & 1,601 \\
\hline Pesca & 1,316 & Química & 1,590 \\
\hline Construção & 1,226 & Outros serviços & 1,470 \\
\hline \multicolumn{4}{|c|}{ Lixa: cidade peri-urbana - pequena } \\
\hline Administração pública & 1,422 & Construção & 1,857 \\
\hline Hotéis e restauração & 1,414 & Outros serviços & 1,641 \\
\hline Outros serviços & 1,287 & Transportes & 1,539 \\
\hline \multicolumn{4}{|c|}{ Esposende: cidade peri-urbana - média } \\
\hline Construção & 1,696 & Outros serviços & 1,531 \\
\hline Maquinaria & 1,419 & Hotéis e restauração & 1,502 \\
\hline Outros serviços & 1,392 & Química & 1,349 \\
\hline
\end{tabular}

Quando se analisam os impactos ao nível do emprego distinguir-se-ão os efeitos multiplicadores dos sectores chave das zonas urbanas e rurais, respectivamente. De acordo com o quadro 4, em termos de impacto no emprego para as zonas urbanas são as actividades ligadas aos serviços que mais efeitos multiplicadores causam secundados pela indústria transfor- 
madora, pelo sector metalúrgico e pela maquinaria. A construção é muito importante em Vila Real e em Esposende. Quando as zonas rurais são tidas em consideração continuam a ser as actividades ligadas aos serviços que mais efeitos multiplicadores em termos de emprego sendo de realçar o facto que a criação de animais só tem feitos multiplicadores significativos em Mirandela - pequena cidade agrícola.

Quadro 4 - Multiplicadores do emprego para sectores chave da zona urbana e rural de cidades portuguesas e seus impactos na outra zona

\begin{tabular}{|c|c|c|c|}
\hline \multicolumn{2}{|c|}{$\begin{array}{l}\text { Impacto no produto na zona urbana e rural causado por } \\
\text { um choque exógeno ocorrido na zona urbana }\end{array}$} & \multicolumn{2}{|c|}{$\begin{array}{c}\text { Impacto no produto na zona urbana e rural causado por } \\
\text { um choque exógeno ocorrido na zona rural }\end{array}$} \\
\hline Sector chave/urbano & $\begin{array}{c}\text { Impacto no } \\
\text { produto na } \\
\text { zona urbana e } \\
\text { rural }\end{array}$ & Sector chave/rural & $\begin{array}{c}\text { Impacto no } \\
\text { produto na } \\
\text { zona urbana e } \\
\text { rural }\end{array}$ \\
\hline \multicolumn{4}{|c|}{ Mirandela: cidade agrícola - pequena } \\
\hline Outros serviços & 1,671 & Outros serviços & 1,685 \\
\hline Energia & 1,329 & Têxteis/madeira e curtumes & 1,526 \\
\hline Hotéis e restauração & 1,257 & Produção animal & 1,511 \\
\hline \multicolumn{4}{|c|}{ Vila Real: cidade agrícola - média } \\
\hline Outros serviços & 1,758 & Transportes e serviços & 2,200 \\
\hline Maquinaria & 1,539 & Maquinaria & 1,957 \\
\hline Construção & 1,293 & Agro-indústrias & 1,814 \\
\hline \multicolumn{4}{|c|}{ Tavira: cidade turística - pequena } \\
\hline Maquinaria & 2,033 & Outros serviços & 1,391 \\
\hline Outros serviços & 1,358 & Agro-indústrias & 1,281 \\
\hline Transportes & 1,315 & Transportes & 1,256 \\
\hline \multicolumn{4}{|c|}{ Silves: cidade turística - média } \\
\hline Química & 1,477 & Outros serviços & 1,438 \\
\hline Outros serviços & 1,421 & Transportes & 1,388 \\
\hline Agro-indústrias & 1,209 & Maquinaria & 1,375 \\
\hline \multicolumn{4}{|c|}{ Lixa: cidade peri-urbana - pequena } \\
\hline Outros serviços & 1,604 & Química & 1,620 \\
\hline Transportes & 1,592 & Outros serviços & 1,612 \\
\hline Sector financeiro & 1,384 & Construção & 1,370 \\
\hline \multicolumn{4}{|c|}{ Esposende: cidade peri-urbana - média } \\
\hline Outros serviços & 1,621 & Outros serviços & 1,672 \\
\hline Maquinaria & 1,566 & Hotéis e restauração & 1,226 \\
\hline Construção & 1,403 & Química & 1,179 \\
\hline
\end{tabular}

\section{CONSIDERAÇÕES FINAIS}

O estudo Marketowns constatou que as empresas localizadas nas áreas urbanas vendem mais, localmente, do que as que desenvolvem a 
sua actividade produtiva nas áreas rurais; constatou, igualmente, que as famílias residentes na cidade consomem mais, localmente, do que as que vivem no meio rural. Por conseguinte, a cidade é o local ideal para sediar empresas, isto é, para fazer novos investimentos.

Apesar desta evidência, os multiplicadores indicam que, embora os multiplicadores da cidade possam ser maiores do que os que se verificam para as áreas rurais, na maior parte das vezes, o efeito multiplicador sentido nas áreas rurais é diminuto. Assim sendo, a retenção dos efeitos na economia local dá-se mais nas áreas urbanas.

No caso das cidades portuguesas, verifica-se o contrário, sobretudo em cidades onde a agricultura é a principal actividade económica desenvolvida pelas populações.

Os resultados obtidos com o cálculo dos multiplicadores permitem quantificar a magnitude das ligações que são apresentadas na Figura 6. De uma maneira geral, resulta que os fluxos de produção e emprego do meio urbano para o rural têm uma menor dimensão do que os que se verificam do meio rural para o urbano. As empresas da cidade não dependem tanto do mundo rural para as suas compras e emprego, como este depende daquele.

Figure 6 - Modelo das possíveis relações entro meio urbano e rural

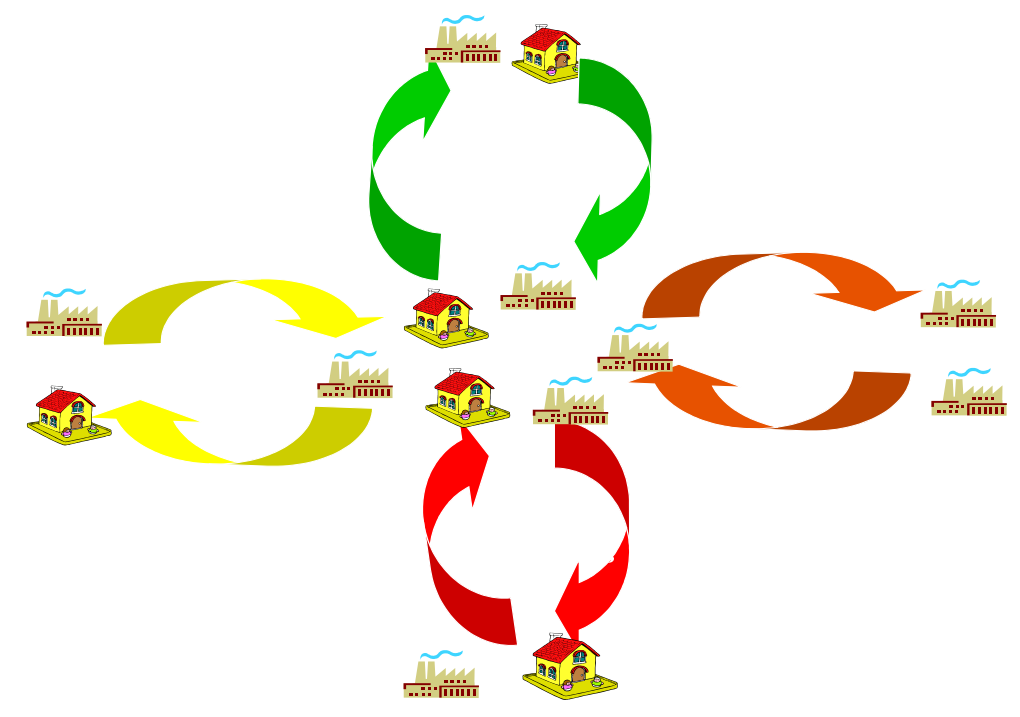

Há um padrão semelhante quando se analisa o rendimento das famílias. Por um lado, o rendimento obtido nas áreas rurais tem um maior impacto; e, por outro lado, os multiplicadores do rendimento das famílias são maiores nas cidades do que no meio rural. Também neste caso, os 
fluxos dentro da cidade ou no mundo rural envolvente são maiores do que os ocorrem entre os dois mundos.

A dimensão dos fluxos de produção dos factores, do emprego e do rendimento são maiores do meio rural para cidade do que em sentido inverso. Os fluxos intra-urbano são, de igual modo superiores aos que vão da cidade para o mundo rural.

Em síntese, pode-se afirmar que, embora os multiplicadores sejam maiores no meio urbano o qual apresenta, por conseguinte, um maior potencial de crescimento, tal facto em pouco contribuirá para um maior desenvolvimento das áreas rurais. Donde será possível concluir que, para se maximizar o potencial de desenvolvimento, há que se proceder a um maior equilíbrio de oportunidades entre os dois mundos.

\section{REFERÊNCIAS}

COURTNEY, P. Small towns and the rural economy: a study of their contemporary functions and potential role in rural development. PhD Thesis, University of Plymouth, UK, 2000.

COURTNEY, P.; ERRINGTON, A. The role of small towns in the local economy and some implications for development policy. Local Economy 15, 280-301, 2000 .

DINIZ, F. Non-farm businesses local economic integration level: the case of six Portuguese small and medium-sized Markettowns - a sectoral approach. In: European Congress of the European Regional Science Association - Regions and Fiscal Federalism, 44., 2004, Porto, Portugal. Anais... Porto: University of Porto, 2004. Participant 665, paper 349.

DINIZ, F.; POETA, A.; SILVA, C.; ANTÓNIO, P.; RIBEIRO, L.; ABREU, S. Study Área Report for Vila Real - Deliverable Eleven. Vila Real: Marketowns, 2003.

DINIZ, F.; POETA, A.; SILVA, C.; ANTÓNIO, P.; RIBEIRO, L.; ABREU, S. National Report for Portugal - Deliverable Twelve. Vila Real: Marketowns, 2003.

ERRINGTON, A. J. Modelling the seamless Web: economic linkages and rural policy. Sociologia Ruralis XXX1-1, 17-26, 1991.

ERRINGTON, A. J. The Peri-urban Fringe: Europe's Forgotten Rural Areas. Journal of Rural Studies, 10, 367-376, 1994.

ERRINGTON, A. J. Small business growth and the maintenance of a vibrant economy in accessible rural areas. In: Roots 1996. Proceedings of the Rural 
Practice Research Conference of the RICS, Cirencester, 5 January 1996. RICS, London.

ERRINGTON, A. J. Rural employment issues in the peri-urban fringe. In: BOLLMAN, R. D.; BRYDEN, J. (Ed.). Rural employment: an international perspective. Wallingford, UK: CAB International, 1997.

ERRINGTON, A. J.; COURTNEY, P. Tracing the 'economic footprint' of market towns. A methodological contribution to rural policy analysis. Agricultural Economics Society, 14-17, Manchester, Apr. 2000.

ERRINGTON, A. J., HARRISON-MAYFIELD, L. E.; JONES, P. J. The employment impact of changing agricultural policy. Research Report No 24. Rural Development Commission, Salisbury, 1996.

HARRIS, R. I. D.; LIU, A. Input-output modelling of the urban and regional economy: the importance of external trade. Regional Studies, 32, p. 851-862, 1998.

HARRISON, L. The impact of the agricultural industry on the rural economy - tracking the spatial distribution of farm outputs and inputs. Journal of Rural Studies, 9, p. 81-88, 1993.

HARRISON, L.; MAYFIELD, L. The local economic impact of small farms: a spatial analysis. Tijdschrift voor Econische en Sociale Geografie 87, p. 387-398, 1996.

MAYFIELD L.; COURTNEY P.; TRANTER R.; JONES P.; FORD S.; AGARWAL S.; MCGEORGE A.; SCHMITT B.; JOBARD M.; LEPICIER D.; TERLUIN I.; VAN LEEUWEN M.; KEFFNER K.; ROSNER A.; CZARNECKI A.; DINIZ F. The Role of Small and Medium-sized Towns in Rural Development. MARKETOWNS, Reading (UK): CAS, University of Reading, 2005. Rapport final du programme, 5 PCRD, QLRT-2000-01923.

PSALTOPOULOS, D.; THOMSON, K. J. Input-Out evaluation of rural development: a forestry-centred application. Journal of Rural Studies, v. 9, n. 4, p. 351-358, 1993.

ROBERTS, D. Rural-urban interdependencies: analysing using an inter-regional SAM model. European Review of Agricultural Economics, 25, p. 506-527, 1998.

ROUND, J. I. Decomposing multipliers for economic systems involving regional and world trade. The Economic Journal 95, p. 383-399, 1985.

ROUND, J. I. Decomposition of Input-Output and Economy-Wide Multipliers in a Regional Setting. In: MILLER, R.E.; POLENSKE, K. R.; ROSE, A. Z. Frontiers of Input-Output Analyses. Oxford, 1989. 
SARACENO, E. Alternative readings of spatial differentiation: the rural versus the local economy. Paper given at the International Agricultural Economics Society Conference, Stresa, 6-10 September1993. 


\section{Anexo I}

\section{Contas da Matriz de Contabilidade Social inter-regional do Projecto Ma- rketowns}

\section{Conta de Produção (17 sectores):}

1. Explorações Agrícolas Extensivas de Terra Arável

2. Explorações de Gado Leiteiro e Intensivas de Terra Arável

3. Horticultura

4. Explorações Agrícolas Mistas

5. Floresta e Pescas

6. Indústria Agro-Alimentar

7. Indústria Extractiva de Carvão, Petróleo, Gás e outras, Electricidade e Águas.

8. Têxtil, Couro, Madeira, Mobiliário, Papel e Tipografia

9. Produtos Químicos, Borracha, Plásticos e Vidro

10. Metalúrgica, Maquinaria, Material Eléctrico, Computadores, Material Óptico e de Transporte

11. Construção

12. Grossistas e Retalhistas

13. Hotéis, Restauração

14. Serviços de Transportes

15. Bancos, Serviços Financeiros e Seguradoras

16. Imobiliário e outros Serviços

17. Administração Pública, Educação, Saúde, Lazer e Cultura

Conta dos Factores de Produção (4 níveis de qualificação):

1. Gestão e profissionais qualificados

2. Não manuais qualificados

3. Manuais qualificados

4. Manuais não qualificados

Conta das Famílias (4 níveis de rendimento das famílias):

1. $1^{\circ}$ Quartil.

2. $2^{\circ}$ Quartil

3. $3^{\circ}$ Quartil

4. $4^{\circ}$ Quartil

\section{Conta Exógena ROW:}

Soma da Conta do Resto do Mundo (importações/exportações/consumo), Conta do Estado (impostos/subsídios) e conta de capital (poupanças /investimentos). 
Anexo 2. Estrutura da Matriz de Contabilidade Social inter-regional para o projecto Marketowns

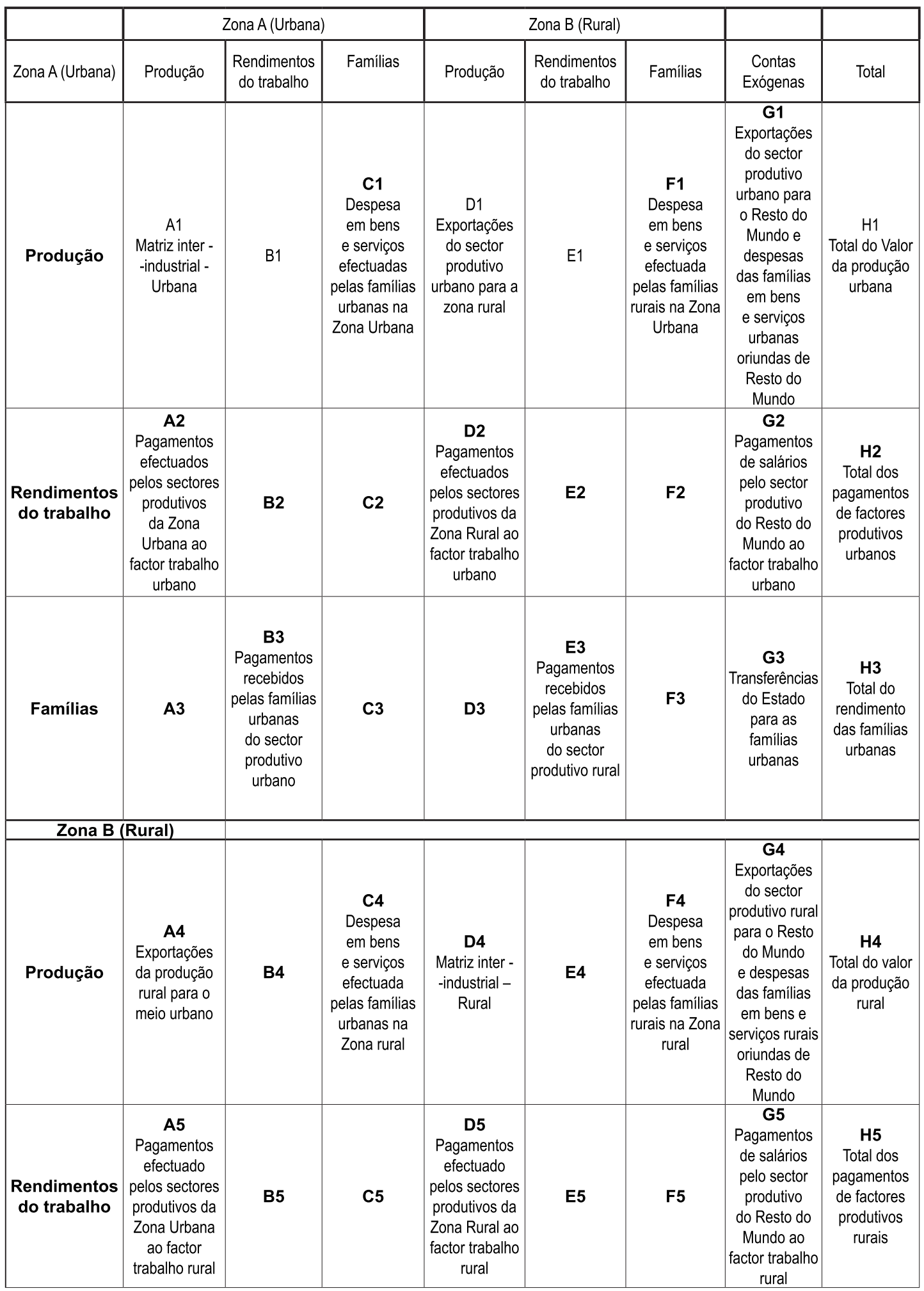




\begin{tabular}{|c|c|c|c|c|c|c|c|c|}
\hline Famílias & A6 & \begin{tabular}{|c|} 
B6 \\
Pagamentos \\
recebidos \\
pelas famílias \\
rurais do \\
sector \\
produtivo \\
urbano \\
\end{tabular} & C6 & D6 & \begin{tabular}{|c|} 
E6 \\
Pagamentos \\
recebi- \\
dos pelas \\
familias rurais \\
do sector \\
produtivo rural
\end{tabular} & F6 & \begin{tabular}{|c|} 
G6 \\
Transferências \\
do Estado \\
para as \\
famílias rurais
\end{tabular} & $\begin{array}{c}\text { H6 } \\
\text { Total do } \\
\text { rendimento } \\
\text { das famílias } \\
\text { rurais }\end{array}$ \\
\hline Total & \begin{tabular}{|c|} 
A8 \\
Total do valor \\
dos inputs \\
do sector \\
produtivo \\
urbano
\end{tabular} & $\begin{array}{c}\text { B8 } \\
\text { Total dos } \\
\text { pagamentos } \\
\text { de factores } \\
\text { produtivos } \\
\text { urbanos }\end{array}$ & $\begin{array}{c}\text { C8 } \\
\text { Despesa total } \\
\text { das famílias } \\
\text { urbanas }\end{array}$ & \begin{tabular}{|c|} 
D8 \\
Total do valor \\
dos inputs \\
do sector \\
produtivo rural
\end{tabular} & $\begin{array}{c}\text { E8 } \\
\text { Total dos } \\
\text { pagamentos } \\
\text { de factores } \\
\text { produtivos } \\
\text { rurais }\end{array}$ & $\begin{array}{c}\text { F8 } \\
\text { Despesa total } \\
\text { das famílias } \\
\text { rurais }\end{array}$ & G8 & H8 \\
\hline
\end{tabular}

64 | Nexos Econômicos - CME-UFBA 
Anexo 3. Fontes para a MCS

\begin{tabular}{|c|c|c|}
\hline Sub-matrriz & Descrição & Dados \\
\hline $\mathrm{A} 1$ & Matriz inter -industrial - Urbana & $\begin{array}{c}\text { Dados input-ouput dos inquéritos às empresas } \\
\text { e Matriz I/O regional }\end{array}$ \\
\hline $\mathrm{A} 2$ & $\begin{array}{c}\text { Pagamentos efectuado pelos sectores } \\
\text { produtivos da Zona Urbana ao factor trabalho } \\
\text { urbano }\end{array}$ & Dados do inquérito às empresas \\
\hline A4 & $\begin{array}{c}\text { Exportações da produção rural para o meio } \\
\text { urbano }\end{array}$ & Dados input-ouput dos inquéritos às empresas \\
\hline A5 & \begin{tabular}{|c|} 
Pagamentos efectuado pelos sectores \\
produtivos da Zona Urbana ao factor trabalho \\
rural
\end{tabular} & Dados do inquérito sobre salários. \\
\hline A7 & $\begin{array}{c}\text { Impostos indirectos, IVA, Subsídios, } \\
\text { importações do Resto do Mundo pelo sector } \\
\text { produtivo urbano }\end{array}$ & $\begin{array}{l}\text { Balanceamento das linhas i.e. Total (A1-A5) } \\
\text { subtraída da A8 }\end{array}$ \\
\hline A8 & $\begin{array}{l}\text { Total do valor dos inputs do sector produtivo } \\
\text { urbano }\end{array}$ & $\begin{array}{l}\text { Total dos inputs das empresas urbanas } \\
\text { retirado da Matriz I/O regional }\end{array}$ \\
\hline B3 & $\begin{array}{l}\text { Pagamentos recebidos pelas famílias urbanas } \\
\text { do sector produtivo urbano }\end{array}$ & Dados do inquérito às empresas e às famílias. \\
\hline B6 & $\begin{array}{c}\text { Pagamentos recebidos pelas famílias rurais do } \\
\text { sector produtivo urbano }\end{array}$ & Dados do inquérito às empresas e às famílias \\
\hline B7 & $\begin{array}{l}\text { Pagamentos a famílias do Resto do Mundo } \\
\text { efectuados pelo sector produtivo urbano }\end{array}$ & $\begin{array}{l}\text { Dados dos inquéritos às empresas e às } \\
\text { famílias. }\end{array}$ \\
\hline B8 & $\begin{array}{c}\text { Total dos pagamentos de factores produtivos } \\
\text { urbanos }\end{array}$ & Soma de B3 + B6 + B7 \\
\hline C1 & $\begin{array}{c}\text { Despesa em bens e serviços efectuadas pelas } \\
\text { famílias urbanas na Zona Urbana }\end{array}$ & $\begin{array}{l}\text { Dados dos inquéritos às famílias e alguns } \\
\text { dados secundários }\end{array}$ \\
\hline C4 & $\begin{array}{l}\text { Despesa em bens e serviços efectuadas pelas } \\
\text { famílias urbanas na Zona rural }\end{array}$ & $\begin{array}{l}\text { Dados dos inquéritos às famílias e alguns } \\
\text { dados secundários }\end{array}$ \\
\hline $\mathrm{C7}$ & $\begin{array}{c}\text { Poupanças/impostos indirectos das famílias } \\
\text { urbanas }\end{array}$ & Dados dos inquéritos às famílias \\
\hline $\mathrm{C} 8$ & Despesa total das famílias urbanas & Soma de C1, C4 e C7 \\
\hline D1 & $\begin{array}{c}\text { Exportações do sector produtivo urbano para } \\
\text { a zona rural }\end{array}$ & Dados input-ouput dos inquéritos às empresas \\
\hline $\mathrm{D} 2$ & $\begin{array}{c}\text { Pagamentos efectuado pelos sectores } \\
\text { produtivos da Zona Rural ao factor trabalho } \\
\text { urbano }\end{array}$ & Dados input-ouput dos inquéritos às empresas \\
\hline D4 & Matriz inter -industrial - Rural & $\begin{array}{c}\text { Dados input-ouput dos inquéritos às empresas } \\
\text { e Matriz I/O regional }\end{array}$ \\
\hline D5 & $\begin{array}{c}\text { Pagamentos efectuado pelos sectores } \\
\text { produtivos da Zona Rural ao factor trabalho } \\
\text { rural }\end{array}$ & Dados input-ouput dos inquéritos às empresas \\
\hline D7 & $\begin{array}{c}\text { Impostos indirectos, IVA, Subsídios, } \\
\text { importações do Resto do Mundo pelo sector } \\
\text { produtivo rural }\end{array}$ & $\begin{array}{l}\text { Balanceamento das linhas, calculado através } \\
\text { da soma de (D1-D5) subtraindo D8 }\end{array}$ \\
\hline D8 & $\begin{array}{l}\text { Total do valor dos inputs do sector produtivo } \\
\text { rural }\end{array}$ & Matriz I/O regional \\
\hline E3 & $\begin{array}{c}\text { Pagamentos recebidos pelas famílias urbanas } \\
\text { do sector produtivo rural }\end{array}$ & Dados input-ouput dos inquéritos às empresas \\
\hline E6 & $\begin{array}{c}\text { Pagamentos recebidos pelas famílias rurais do } \\
\text { sector produtivo rural }\end{array}$ & Dados input-ouput dos inquéritos às empresas \\
\hline
\end{tabular}




\begin{tabular}{|c|c|c|}
\hline E7 & $\begin{array}{c}\text { Pagamentos a famílias do Resto do Mundo } \\
\text { efectuados pelo sector produtivo rural }\end{array}$ & Dados input-ouput dos inquéritos às empresas \\
\hline E8 & $\begin{array}{c}\text { Total dos pagamentos de factores produtivos } \\
\text { rurais }\end{array}$ & Soma de E3 + E6 + E7 \\
\hline
\end{tabular}

\begin{tabular}{|c|c|c|}
\hline $\mathrm{F} 1$ & $\begin{array}{l}\text { Despesa em bens e serviços efectuada pelas } \\
\text { famílias rurais na Zona Urbana }\end{array}$ & $\begin{array}{l}\text { Dados do inquérito às famílias e alguns dados } \\
\text { secundários }\end{array}$ \\
\hline $\mathrm{F} 4$ & $\begin{array}{l}\text { Despesa em bens e serviços efectuada pelas } \\
\text { famílias rurais na Zona rural }\end{array}$ & $\begin{array}{l}\text { Dados do inquérito às famílias e alguns dados } \\
\text { secundários }\end{array}$ \\
\hline $\mathrm{F} 7$ & $\begin{array}{l}\text { Poupanças/impostos indirectos das famílias } \\
\text { rurais }\end{array}$ & $\begin{array}{l}\text { Dados do inquérito às famílias e alguns dados } \\
\text { secundários }\end{array}$ \\
\hline F8 & Despesa total das familias rurais & Soma de F1 + F4 + F7 \\
\hline G1 & $\begin{array}{c}\text { Exportações do sector produtivo urbano para } \\
\text { ROW e despesas das famílias em bens e } \\
\text { serviços urbanas oriundas de ROW }\end{array}$ & Dados do inquérito às empresas e às famílias \\
\hline G2 & $\begin{array}{l}\text { Pagamentos de salários pelo sector produtivo } \\
\text { do Resto do Mundo ao factor trabalho urbano. }\end{array}$ & Dados do inquérito às empresas e às famílias \\
\hline G3 & $\begin{array}{c}\text { Transferências do Estado para as famílias } \\
\text { urbanas }\end{array}$ & Estimado dos inquéritos às famílias \\
\hline G4 & $\begin{array}{l}\text { Exportações do sector produtivo rural para } \\
\text { ROW e despesas das famílias em bens e } \\
\text { serviços rurais oriundas de Resto do Mundo }\end{array}$ & Dados do inquérito às empresas e às famílias \\
\hline G5 & $\begin{array}{l}\text { Pagamentos de salários pelo sector produtivo } \\
\text { do Resto do Mundo ao factor trabalho rural }\end{array}$ & Dados do inquérito às empresas e às famílias \\
\hline G6 & $\begin{array}{c}\text { Transferências do Estado para as famílias } \\
\text { rurais }\end{array}$ & Estimado dos inquéritos às famílias \\
\hline $\mathrm{H} 1$ & Total do Valor da produção urbana & Matriz I/O regional \\
\hline $\mathrm{H} 2$ & $\begin{array}{l}\text { Total dos pagamentos de factores produtivos } \\
\text { urbanos }\end{array}$ & Soma de A2 + D2+ G2 \\
\hline $\mathrm{H} 3$ & Total do rendimento das famílias urbanas & Soma de $\mathrm{B} 3+\mathrm{E} 3+\mathrm{G} £$ \\
\hline $\mathrm{H} 4$ & Total do Valor da produção rural & Matriz I/O regional \\
\hline $\mathrm{H} 5$ & $\begin{array}{c}\text { Total dos pagamentos de factores produtivos } \\
\text { rurais }\end{array}$ & Soma de A5 + D5 + G5 \\
\hline $\mathrm{H} 6$ & Total do rendimento das famílias rurais & Soma de B6 + E6 + G6 \\
\hline
\end{tabular}

